\title{
Usulan Perbaikan Pada Penerapan Sistem Manajemen Keselamatan Dan Kesehatan Kerja Di PT. Surya Toto Indonesia Tbk Divisi Sanitary Dengan Metode HIRA Dan FTA
}

\section{Proposed Improvements On The Implementation Of Occupational Health And Safety Management System In PT. Surya Toto Indonesia Tbk Sanitary Division With HIRA And FTA Methods}

\author{
Nur Fadilah Fatma ${ }^{1}$, Dhimas Eka Mustafa Putra ${ }^{2}$ \\ 1,2. Program Studi Teknik Industri, Fakultas Teknik, Universitas Muhammadiyah Tangerang \\ ${ }^{1}$ nurfadilahfatma@gmail.com
}

\begin{abstract}
Identification of potential hazards and risk assessments are part of the occupational safety and health program in the risk management stage, which is conducted in an effort to prevent work accidents and occupational illness. The purpose of this research is to identify the potential hazard in PT Surya Toto Indonesia Tbk Sanitary division and analyze the root cause and give suggestion of improvement. Location and time of observation is PT Surya Toto Indonesia Tbk in April until May 2017. Object of observation is potential danger in section Slip Preparing PT Surya Toto Indonesi Tbk. The methods used by the researchers are HIRARC and FTA. The identification of potential hazards and risk assessments undertaken by researchers together with experts, which in this case are OSH officers and local supervisors, resulted in 25 different risks. With the following division, 2 low risk level, 10 medium level risk, 11 high risk level and 2 extreme level risk. After handling by the management of the company against the risk of extreme and high level, there is risk to be 2 high risk and 11 medium level risks. To reduce the value of risk, companies can make safer working conditions and better supervision of employee's unsafe behavior.
\end{abstract}

Keywords: Hazard Potential Identification, Risk Assessment, SMK3, HIRARC, FTA

\section{ABSTRAK}

Identifikasi potensi bahaya dan penilaian risiko merupakan bagian dari program keselamatan dan kesehatan kerja dalam tahapan manajemen risiko, yang dilakukan sebagai upaya untuk mencegah terjadinya kecelakaan kerja dan penyakit akibar kerja (PAK). Tujuan dari penelitian ini adalah mengidentifikasi potensi bahaya yang terdapat di PT Surya Toto Indonesia Tbk divisi Sanitary dan menganalisa akar penyebabnya serta memberikan usulan perbaikan. Lokasi dan waktu pengamatan adalah PT Surya Toto Indonesia Tbk pada bulan April sampai bulan Mei 2017. Obyek pengamatan adalah potensi bahaya di seksi Slip Preparing PT Surya Toto Indonesi Tbk. Metode yang digunakan oleh peneliti adalah HIRARC dan FTA. Pelaksanaan identifikasi potensi bahaya dan penilaian risiko yang dilakukan oleh peneliti bersama dengan para ahli, yang dalam hal ini adalah petugas K3 dan supervisor setempat, menghasilkan 25 macam risiko. Dengan pembagian sebagai berikut, 2 risiko tingkat rendah, 10 risiko tingkat sedang, 11 risiko tingkat tinggi dan 2 risiko tingkat ekstrim. Setelah dilakukan penanganan oleh manajemen perusahaan terhadap risiko tingkat ekstrim dan tinggi maka risiko ada menjadi 2 risiko tingkat tinggi dan 11 risiko tingkat sedang. Untuk mengurangi nilai risiko, perusahaan dapat membuat ketentuan kerja yang lebih aman dan pengawasan yang lebih baik lagi terhadap perilaku tidak aman dari karyawan.

Kata Kunci: Identifikasi Potensi Bahaya, Penilaian Risiko, SMK3, HIRARC, FT 


\section{PENDAHULUAN}

\subsection{Latar Belakang}

Kekuatan yang ada dalam suatu perusahaan salah satunya terletak pada orang-orang yang ada dalam perusahaan tersebut. Apabila tenaga kerja diperlakukan secara tepat dan sesuai kebutuhan, perusahaan akan mencapai hasil yang sesuai dengan tujuan yang diinginkan oleh perusahaan. Dari uraian tersebut jelaslah bahwa faktor sumber daya manusia memegang peranan yang paling penting dan utama dalam proses produksi, karena alat produksi tidak akan berjalan tanpa dukungan dan keberadaan sumber daya manusia.

Penciptaan keselamatan dan kesehatan kerja dalam lingkungan perusahaan, akan berdampak pada kualitas kesehatan para pekerjanya. Dengan memiliki pekerja yang sehat, maka mereka bisa bekerja secara optimal. Oleh karena itu, bagi sebuah perusahaan diwajibkan untuk mempertimbangkan masalah keselamatan dan kesehatan kerja. Bukan sekedar untuk mematuhi peraturan pemerintah yang dicantumkan dalam undang- undang industri dan peraturan tentang ketenagakerjaan. Melainkan karena pada dasarnya pemenuhhan kewajiban ini demi untuk kepntingan perusahaan itu sendiri.

Keselamatan dan kesehatan kerja menunjuk kepada kondisi-kondisi fisiologis-fisikal dan psikologis tenaga kerja yang diakibatkan oleh lingkungan kerja yang disediakan oleh perusahaan. Kondisi fisiologis-fisikal meliputi penyakit-penyakit dan kecelakaan kerja seperti kehilangan nyawa atau anggota badan, cedera, sakit punggung, dan sebagainya. Kondisi-kondisi psikologis diakibatkan oleh stres pekerjaan dan kehidupan kerja yang berkualitas rendah, seperti ketidakpuasan, sikap apatis, mudah marah, mudah putus asa, dan lain-lain.

Dalam proses produksinya, PT Surya Toto Indonesia Tbk sudah menggunakan teknologi modern. Banyak mesin-mesin besar yang digunakan seperti mesin penggiling bahan baku yang masih berupa bongkahan batu dengan ukuran yang cukup besar, mesin mixer bahan baku, mesin boiler, mesin pemotong besi, mesin gerinda dll. Dengan adanya mesin-mesin itu maka potensi bahaya dan kecelakaan kerja yang ada di proses produksi PT Surya Toto Indonesia Tbk divisi Sanitary sangat penting untuk diidentifikasi dan dianalisa.

Dengan adanya berbagai tuntutan tentang masalah kesehatan dan keselamatan kerja, maka perusahaan harus dapat memenuhi tanggung jawabnya dalam memberikan perlindungan pada karyawan dengan melakukan program-program tentang kesehatan dan keselamayan kerja. Karena pada proses produksi menggunakan mesin dan pekerjaan di setiap proses mempunyai resiko kecelakaan kerja dan potensi sumber bahaya yang berbeda-beda maka perlu dilakukan pengendalian kecelakaan kerja dan potensi sumber bahaya menggunakan metode HIRARC (Hazard Identification, Risk Assessment and Risk Control).

Manfaat risiko sangat penting bagi keberlangsungan suatu usaha atau kegiatan dan merupakan alat untuk melindungi perusahaan dari setiap kemungkinan yang merugikan. Manajemen tidak cukup melakukan langkah-langkah pengamanan yang memadai sehingga peuluang terjadinya bencana semakin besar (Ramli,2010). Metode ini dapat digunakan untuk menganalisa potensi bahaya dari aktivitas kerja serta memberikan penilaian resiko terhadap suatu pekerjaan.

\subsection{Identifikasi Masalah}

Banyaknya mesin-mesin besar dan alat-alat pengangkut bahan baku yang beroperasi di area bahan baku serta kondisi lokasi yang berdebu dan memiliki ruang terbuka yang cukup luas membuat lokasi kerja pengolahan bahan baku memiliki banyak potensi bahaya yang perlu diidentifikasi dan dinilai tingkat risikonya. Sistem Manajemen Keselamatan dan Kesehatan Kerja yang sudah berjalan di PT Surya Toto Indonesia Tbk belum melakukan identifikasi secara spesifik terhadap risiko dan potensi bahaya yang ada. Maka perlunya membuat identifikasi bahaya dan penilaian risiko untuk lokasi tersebut agar memudahkan dalam melihat tingkat risiko dan proses kerja apa saja yang memiliki risiko bahaya dan kecelakaan kerja 
dari tingkat rendah sampai tingkat tinggi serta untuk memudahkan untuk mencari cara untuk mengurangi tingkat risiko yang tinggi yang terdapat di lokasi kerja PT Surya Toto Indonesia Tbk divisi Sanitary.

\subsection{Rumusan Masalah}

Berdasarkan uraian di bagian latar belakang mengenai arti pentingnya kesehatan dan keselamatan kerja bagi kemajuan peusahaan dan identifikasi masalah diatas, maka rumusan masalah dalam penelitian ini adalah:

1. Bagaimana penerapan Sistem Manajemen Keselamatan dan Kesehatan Kerja di PT Surya Toto Indonesia Tbk divisi Sanitary?

2. Apa saja risiko dan potensi bahaya yang terdapat di PT Surya Toto Indonesia Tbk divisi Sanitary?

3. Bagaimana penanganan terhadap potensi bahaya yang ada yang sudah dilakukan oleh PT Surya Toto Indonesia Tbk divisi Sanitary saat ini?

4. Bagaimana usulan perbaikan terhadap potensi bahaya yang ada di PT Surya Toto Indonesia Tbk divisi Sanitary?

\subsection{Tujuan Penelitian}

Adapun khusus dari penelitian ini adalah sebagai berikut:

1. Mengetahui penerapan Sistem Manajemen Keselamatan dan Kesehatan Kerja di PT Surya Toto Indonesia Tbk divisi Sanitary

2. Mengetahui risiko dan potensi bahaya yang terdapat di PT Surya Toto Indonesia Tbk divisi Sanitary

3. Mengetahui cara PT Surya Toto Indonesia Tbk divisi Sanitary melakukan penanganan terhadap potensi bahaya yang ada

\section{METODOLOGI}

\subsection{Landasan Teori}

Sistem Manajamene Keselamatan dan Kesehatan Kerja adalah bagian dari sistem manajemen perusahaan secara keseluruhan yang meliputi struktur organisasi, perencanaan, pelaksanaan, tanggung jawab, prosedur, proses dan sumber daya yang dibutuhkan bagi pengembangan, penerapan, pencapaian, pengkajian dan pemeliharaan kebijakan keselamatan dan kesehatan kerja dalam rangka pengendalian risiko yang berkaitan dengan kegiatan kerja guna terciptanya tempat kerja yang aman, efisien dan produktif.

HIRARC (Hazard Identification Risk Assesment and Risk Control) adalah serangkaian proses mengidentifikasi bahaya yang dapat terjadi dalam aktifitas rutin ataupun non rutin di perusahaan kemudian melakukan penilaian risiko dari bahaya tersebut lalu membuat program pengendalian bahaya tersebut agar dapat diminimalisir tingkat risikonya ke yang lebih rendah dengan tujuan dengan tujuan mencegah terjadi kecelakaan. Implementasi K3 dimulai dengan perencanaan yang baik meliputi identifikasi bahaya, penilaian risiko. HIRARC inilah yang menentukan arah penerapan $\mathrm{K} 3$ dalam perusahaan sehingga perusahaan nantinya akan menyelesaikan masalahnya sendiri terutama masalah manajemen (Ramli, 2010)

FTA (Fault Tree Analysis) merupakan sebuah alat analisa yang menerjemahkan secara grafik kombinasi-kombinasi kesalahan yang menyebabkan kegagalan dari sistem. FTA menggunakan dua simbol utama yang disebut event dan gates. Ada tiga tipe event, yaitu:

1. Primary Event adalah sebuah tahap dalam proses penggunaan produk yang mungkin saat gagal. Sebagai contoh saat memasukan kunci ke dalam gembok, kunci tersebut mungkin gagal untuk pas atau sesuai dengan gembok. Primery event lebih lanjut dibagi menjadi tiga kategori yaitu:
a. Basic event,
b. Undeveloped event, 
c. External event.

2. Intermediate Event adalah hasil dari kombinsi kesalahan-kesalahan, beberapa diantaranya mungkin primary event. Intermediate event ditempatkan di tengahtengah sebuah fault tree

3. Expanded Event membutuhkan sebuah fault tree yang terpisah dikarenakan kompleksitasnva. Untuk fault tree yang baru ini, expended event adalah undesired event dan diletakan pada bagian atas fault tree.

Dalam pembuatan fault tree dibutuhkan simbol- simbol yang dapat menunjukan identitas dari event ataupun gates seperti yang ada pada Tabel berikut.

Tabel 1. Simbol Fault Tree Analysis

\begin{tabular}{|l|l|}
\hline \multicolumn{1}{|c|}{ Simbol } & \multicolumn{1}{|c|}{ Pengertian/Arti } \\
\hline & $\begin{array}{l}\text { Kejadian yang tidak dikehendaki } \\
\text { sebagai penyebab dasar }\end{array}$ \\
\hline & $\begin{array}{l}\text { Kejadian yang tidak akan dikembangkan lebih } \\
\text { jauh }\end{array}$ \\
\hline & $\begin{array}{l}\text { Menunjukan bahwa uraian lanjutan kegiatan } \\
\text { berada dihalaman ini }\end{array}$ \\
\hline & $\begin{array}{l}\text { Kejadian diatas muncul hanya salah satu yang } \\
\text { dapat menyebabkan kejadian (atau) }\end{array}$ \\
\hline & $\begin{array}{l}\text { Kejadian diatas timbul jika semua input } \\
\text { bersama menyebabkan kejadian diatasanya } \\
\text { (dan) }\end{array}$ \\
\hline
\end{tabular}

\subsection{Data dan Informasi}

Pada tahap ini, dilakukan suatu pengamatan berdasarkan uraian latar belakang permasalahan yang telah ditentukan. Dengan melihat kondisi tingkat produktifitas perusahaan adalah suatu hal yang mendasar diperlukan sebagai upaya proses peningkatan produktifitas dan perbaikan sistem perusahaan secara berkelanjutan.

Pada tahap ini juga, menentukan permasalahan yang diketahui kemudian dibahas dan diuraikan sesuai dengan metode - metode ilmiah yang berhubungan dan mendukung permasalahan yang timbul. Mengumpulkan literatur - literatur yang ada sebagai bahan penunjang proses penyelesaian masalah yang dihadapi. Informasi studi literatur diambil dari buku, referensi dan jurnal penelitian yang akan menunjang langkah - langkah dalam penelitian penyelesaian masalah. Metode dalam penelitian ini menggunakan metode HIRARC dan FTA.

\subsection{Teknik Pengumpulan Data}

Pengambilan data primer dalam penelitian ini diperoleh dari hasil pengamatan langsung dan brainstorming dengan pihak K3L dan karyawan di bagian tersebut, sedangkan data sekunder dalam penelitian ini yakni struktur P2K3 PT Surya Toto Indonesia Tbk divisi Sanitary, data kecelakaan kerja di PT Surya Toto Indonesia Tbk divisi Sanitary, data hasil pengukuran kebisingan di area Slip Preparing tahun 2014 sampai tahun 2016, data hasil pengukuran debu di area Slip Preparing tahun 2014 sampai tahun 2016, proses kerja seksi Slip Preparing, jam kerja karyawan seksi Slip Preparing dan mesinmesin yang diguakan di bagian tersebut di PT Surya Toto Indonnesia Tbk divisi Sanitary. 


\subsection{Analisis dan Pengolahan Data}

Pada tahap ini merupakan tahapan dimana terjadi proses evaluasi terhadap bahaya yang ada pada proses produksi diawali dengan mengidentifikasi bahaya potensial dengan metode HIRARC untuk menganalisa potensi bahaya dari aktivitas kerja serta memberikan penilaian resiko terhadap suatu pekerjaan, lalu dilanjutkan identifikasi dengan metode FTA yang digunakan untuk menentukan akar penyebab masalah pada jenis pekerjaan yang menimbulkan tingkat resiko tinggi atau ekstrim dan dilanjutkan dengan penilaian risiko berdasarkan pengendalian yang sudah dilakukan manajemen perusahaan dan memberikan usulan perbaikan untuk lebih meningkatkan pengendalian yang ada dan lebih mengurangi nilai dan tingkatan risiko yang sudah teridentifikasi.

Metode HIRARC memberikan rekomendasi yang dapat digunakan untuk pencegahan terjadinya kecelakaan kerja. Dari hasil identifikasi menggunakan metode HIRARC jika ditemukan tingkat resiko tinggi atau ekstrim didalamnya, tingkat resiko tinggi atau ekstrim adalah resiko yang memerlukan pertimbangan untuk tindakan lebih lanjut, tetapi biaya pencegahan dan waktu diperlukan harus diperhitungkan dengan teliti dan dibatasi. Tingkat resiko tinggi atau ekstrim berkaitan dengan konsekuensi yang sungguh-sungguh penuh bahaya (extremely harmful), maka penilaian lebih lanjut perlu dilakukan untuk mengetahui dengan tepat

kemungkinan terjadinya bahaya untuk memperoleh ukuran pengendalian yang diperlukan. Hasil dari tingkat resiko tinggi atau ekstrim tersebut langsung di identifikasi kembali menggunakan metode FTA (Fault Three Analysis) untuk menentukan akar penyebab masalah pada jenis pekerjaan yang menimbulkan tingkat resiko tersebut. Adapun langkahlangkahnya adalah sebagai berikut:

1. Mengidentifikasi bahaya potensial dengan menggunakan metode HIRARC

a. Melakukan identifikasi terhadap semua pekerjaan ataupun cara kerja yang mengandung potensi bahaya. Pekerjaan ataupun cara kerja yang mengandung potensi bahaya yang dimaksud adalah pekerjaan ataupun cara kerja yang dapat menimbulkan cidera ringan, sedang maupun parah terhadap pekerja yang melakukannya, contohnya seperti pekerjaan atau cara kerja yang berpotensi pekerja tersebut untuk terbentur, tersandung, terkilir, terjepit, tergilas, tertabrak dan lainlain. Sedangkan dampak merupakan akibat yang timbuk karena adanya potensi bahaya, contohnya "tulang jari tangan pekerja remuk akibat mesin".

b. Identifikasi yang dilakukan dengan didampingi oleh pimpinan bagian tersebut agar semua pekerjaan yang diidentifikasi hanya pekerjaan yang menjadi tanggung jawab bagian tersebut sehingga tidak meluas ke bagian atau area kerja lain.

2. Melakuakn penilaian Saverity dan Likelyhood

a. Saverity (Keparahan) disini menunjukan seberapa parah konsekuensi atau seberapa besar dampak yang ditimbulkan akibat dari potensi bahaya yang ada pada setiap pekerjaan ataupun cara kerja yang mengandung potensi bahaya yang sudah diidentifikasi.

b. Likelyhood (Peluang) disini menunjukan seberapa besar peluang kemungkinan akibat dari potensi bahaya tersebut terjadi. Untuk menentukan nilai likelyhood peneliti menggunakan pertimbangan frekuensi pekerjaan dan jumlah karyawan yang melakukan pekerjaan tersebut.

c. Penilaian risiko merupakan hasil perkhitungan dari:

\section{Paparan x Peluang $x$ Konsekuensi $=$ Nilai Risiko}

Untuk menentukan konsekuensi, harus membuat ketetapan pada severity yang berpotensi terjadi. Faktor- faktor yang dapat mempengaruhi konsekuensi yang harus dipertimbangkan adalah:

1. Potensi pada reaksi berantai, dimana sebuah bahaya jika tidak dihilangkan, akan mengakibatkan kondisi yang lebih berat.

2. Konsentrasi substansi

3. Volume material

4. Kecepatan proyektil dan pergerakan bagiannya 
5. Ketinggian, akibat yang dihasilkan benda yang jatuh ditentukan dari benda itu semula, begitu pula orang yang jatuh dari ketinggian.

6. Jarak pekerja dari bahaya potensial

7. Berat, untuk kejadian tertimpa benda sangat dipengaruhi berat benda tersebut.

8. Tingkat gaya dan energi, misalnya semakin tinggi volume listrik maka semakin tinggi akibat yang dihasilkan jika tersetrum.

3. Menentukan pengedalian risiko

Menentukan pengedalian terhadap risiko tingkat ekstrim dan tinggi yang telah dianalisa dengan metode Fault Tree Analysis (FTA). Pengendalian meliputi pengendalian yang sudah disiapkan oleh perusahaan dan penambahan pengendalian, untuk mengurangi nilai dan tingkatan risiko yang ada.

\subsection{Tahapan Penelitian}

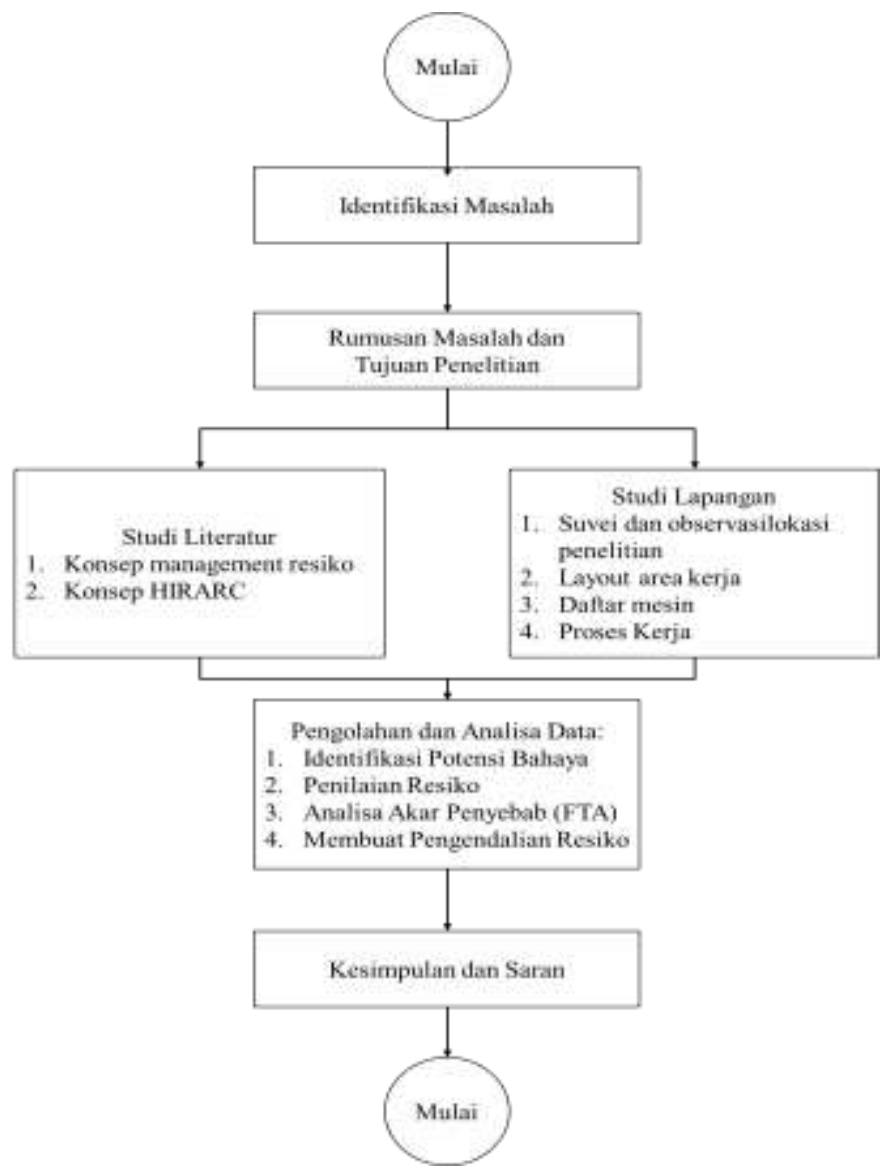

Gambar 1. Alur Proses penelitian 


\section{HASIL DAN PEMBAHASAN}

\subsection{Identifikasi Potensi Bahaya}

Pada tahapan ini dilakukan identifikasi bahaya di area produksi divisi sanitary.

Dimana yang diidentifikasi adalah berkaitan dengan aktivitas, proses kerja, identifikasi bahaya dan resikonya. Dibawah ini table dari identifikasi bahaya.

Tabel 1. Identifikasi Bahaya

\begin{tabular}{|c|c|c|c|c|}
\hline No & Identifikasi Aktivitas & Proses Kerja & Identifikasi Bahaya & Risiko \\
\hline 1 & $\begin{array}{l}\text { Lokasi tombol power bertegangan } \\
\text { ( } 880 \text { Volt) mesin vibrating sieve } \\
\text { berada di bawah mesin dan tidak } \\
\text { ada penutupnya }\end{array}$ & $\begin{array}{l}\text { Penyaringan Slip } \\
\text { kasar menjadi Slip } \\
\text { halus }\end{array}$ & $\begin{array}{l}\text { Tombol power mesin } \\
\text { terkena air dan terjadi } \\
\text { konsleting listrik, } \\
\text { mengakibatkan orang } \\
\text { disekitar mesin } \\
\text { tersebut tersengat } \\
\text { listrik }\end{array}$ & Kematian \\
\hline 2 & Petugas melepas ganjal $V$-Belt & $\begin{array}{l}\text { Pembuatan Cairan } \\
\text { KD }\end{array}$ & $\begin{array}{l}\text { Tangan ikut ke dalam } \\
\text { putaran } V \text {-Belt }\end{array}$ & Kehilangan anggota tubuh \\
\hline 3 & $\begin{array}{l}\text { Petugas standby di area Jaw } \\
\text { Crusher }\end{array}$ & $\begin{array}{l}\text { Giling bongkahan } \\
\text { bahan baku }\end{array}$ & $\begin{array}{l}\text { Terpapat debu dan } \\
\text { terpapar kebisingan }\end{array}$ & $\begin{array}{l}\text { Cidera karena bagian } \\
\text { tubuh masuk kedalam } \\
\text { Ballmill dan terbentur } \\
\text { besi area sekitar mulut } \\
\text { Ballmill }\end{array}$ \\
\hline 4 & $\begin{array}{l}\text { Pemindahan hasil giling dengan } \\
\text { menggunakan sovel loader ke } \\
\text { gudang bahan baku }\end{array}$ & $\begin{array}{l}\text { Giling bongkahan } \\
\text { bahan baku }\end{array}$ & $\begin{array}{l}\text { Terpapar debu, tidak } \\
\text { ada rambu-rambu } \\
\text { untuk manusia untuk } \\
\text { manusia dilarang } \\
\text { melintas di jalur } \\
\text { sovel loader }\end{array}$ & $\begin{array}{l}\text { Cidera karena bagian } \\
\text { tubuh masuk kedalam } \\
\text { Ballmill dan terbentur } \\
\text { besi area sekitar mulut } \\
\text { Ballmill }\end{array}$ \\
\hline 5 & $\begin{array}{l}\text { Pemasangan hopper pada lubang } \\
\text { Ballmill }\end{array}$ & $\begin{array}{l}\text { Persiapan } \\
\text { pembuatan KD cair, } \\
\text { slip dan glaze }\end{array}$ & $\begin{array}{l}\text { Pandangan ke arah } \\
\text { depan terhalang } \\
\text { hopper }\end{array}$ & $\begin{array}{l}\text { Kaki terperosok kedalam } \\
\text { lubang ballmill }\end{array}$ \\
\hline 6 & $\begin{array}{l}\text { Penuangan bahan KD, Slip dan } \\
\text { glaze kedalam hopper }\end{array}$ & $\begin{array}{l}\text { Persiapan } \\
\text { pembuatan KD cair, } \\
\text { slip dan glaze }\end{array}$ & $\begin{array}{l}\text { Mobil sovel loader } \\
\text { menabrak area } \\
\text { penuangan bahan } \\
\text { baku KD, Petugas } \\
\text { terpapar debu bahan } \\
\text { KD yang di tuang, } \\
\text { Tidak ada rambu- } \\
\text { rambu untuk manusia } \\
\text { dilarang melintas di } \\
\text { jalur sovel loader }\end{array}$ & $\begin{array}{l}\text { Cidera karena menabrak } \\
\text { area penuangan bahan } \\
\text { baku KD, gangguan } \\
\text { pernafasan, cacat karena } \\
\text { tertabrak mobil sovel } \\
\text { loader }\end{array}$ \\
\hline 7 & $\begin{array}{l}\text { Petugas membersihkan mulut } \\
\text { tutup Ballmill }\end{array}$ & $\begin{array}{l}\text { Persiapan } \\
\text { pembuatan KD cair, } \\
\text { slip dan glaze }\end{array}$ & $\begin{array}{l}\text { Petugas lain menekan } \\
\text { tombol operasional } \\
\text { ballmil karena panel } \\
\text { ballmill tidak dalam }\end{array}$ & $\begin{array}{l}\text { Kaki patah hingga } \\
\text { kematian }\end{array}$ \\
\hline 8 & Pencucian ruang mesin Blunger & Cuci mesin blunger & $\begin{array}{l}\text { Ruang mesin gelap } \\
\text { Kepala terbentur } \\
\text { baling-baling tajam } \\
\text { Tidak ada tanda saat } \\
\text { pembersihan } \\
\text { berlangsung }\end{array}$ & $\begin{array}{l}\text { Kepala sobek/cidera di } \\
\text { kepala karena } \\
\text { menghantap baling-baling } \\
\text { di dalam mesin Blunger }\end{array}$ \\
\hline 9 & $\begin{array}{l}\text { Instalasi perpipaan berada } \\
\text { dipermukaan lantai }\end{array}$ & $\begin{array}{l}\text { Penyaringan Slip } \\
\text { kasar menjadi Slip } \\
\text { halus }\end{array}$ & $\begin{array}{l}\text { Tersandung saat } \\
\text { berjalan }\end{array}$ & $\begin{array}{l}\text { Luka-luka karena } \\
\text { menbrak mesin-mesin } \\
\text { atau pipa yang ada } \\
\text { disekitar area tersebut }\end{array}$ \\
\hline
\end{tabular}


Tabel 1. Identifikasi Bahaya (Lanjutan)

\begin{tabular}{|c|c|c|c|c|}
\hline No & Identifikasi Aktivitas & Proses Kerja & Identifikasi Bahaya & Risiko \\
\hline 10 & Setting dan cuci mesin Desva & $\begin{array}{l}\text { Aduk kude glaze } \\
\text { dan pembuatan Lem }\end{array}$ & $\begin{array}{l}\text { Tangan terkena mata } \\
\text { pisau mesin Desva }\end{array}$ & $\begin{array}{l}\text { Tangan sobek akibat } \\
\text { terkena mata pisau yang } \\
\text { tajam }\end{array}$ \\
\hline 11 & $\begin{array}{l}\text { Petugas menuangkan air ke dalam } \\
\text { Ballmil }\end{array}$ & $\begin{array}{l}\text { Pembuatan Cairan } \\
\text { KD, Slip, dan Glaze }\end{array}$ & $\begin{array}{l}\text { Kaki terpeleset ke } \\
\text { dalam mulut Ballmill }\end{array}$ & $\begin{array}{l}\text { Cidera pada kepala dan } \\
\text { kaki akibat terpeleset ke } \\
\text { dalam mulut Ballmill }\end{array}$ \\
\hline 12 & $\begin{array}{l}\text { Terdapat undakan pada tangga } \\
\text { menuju ke area Ballmill namun } \\
\text { tidak ada penutupnya saat tidak } \\
\text { digunakan }\end{array}$ & $\begin{array}{l}\text { Pembuatan Cairan } \\
\text { KD, Slip, dan Glaze }\end{array}$ & $\begin{array}{l}\text { Orang disekitar dapat } \\
\text { terjatuh karena lalai } \\
\text { atau sedang tidak } \\
\text { fokus }\end{array}$ & $\begin{array}{l}\text { Cidera, luka- luka, luka } \\
\text { serius di bagian kepala }\end{array}$ \\
\hline 13 & $\begin{array}{l}\text { Penuangan bahan Alumina dan } \\
\text { Kaolin }\end{array}$ & $\begin{array}{l}\text { Pembuatan Cairan } \\
\text { Alumina }\end{array}$ & $\begin{array}{l}\text { Petugas yang berada } \\
\text { di area tersebut } \\
\text { terpapar debu silica }\end{array}$ & $\begin{array}{l}\text { Terjangkit penyakit } \\
\text { Silicosis akibat paparan } \\
\text { debu silica }\end{array}$ \\
\hline 14 & $\begin{array}{l}\text { Petugas menuangkan bongkahan } \\
\text { bahan baku kedalam hopper } \\
\text { mesin Jaw Crusher }\end{array}$ & $\begin{array}{l}\text { Giling bongkahan } \\
\text { bahan baku }\end{array}$ & $\begin{array}{l}\text { Mobil loader } \\
\text { menabrak mesin Jaw } \\
\text { Crusher, petugas } \\
\text { tertimpa muatan } \\
\text { bongkahan bahan } \\
\text { baku }\end{array}$ & $\begin{array}{l}\text { Cidera, kaki patah, luka } \\
\text { kepala }\end{array}$ \\
\hline 15 & $\begin{array}{l}\text { Bembuka mulut Ballmill dengan } \\
\text { kunci khusus }\end{array}$ & $\begin{array}{l}\text { Persiapan } \\
\text { pembuatan KD cair, } \\
\text { slip dan glaze }\end{array}$ & $\begin{array}{l}\text { Cengkraman petugas } \\
\text { saat memutar kunci } \\
\text { khusus terlepas/ } \\
\text { terpeleset }\end{array}$ & $\begin{array}{l}\text { Cidera karena bagian } \\
\text { tubuh masuk kedalam } \\
\text { Ballmill dan terbentur } \\
\text { besi area sekitar mulut } \\
\text { Ballmill }\end{array}$ \\
\hline 16 & $\begin{array}{l}\text { Ukur ketinggian slip di dalam } \\
\text { Ballmill }\end{array}$ & $\begin{array}{l}\text { Persiapan } \\
\text { pembuatan KD cair, } \\
\text { slip dan glaze }\end{array}$ & $\begin{array}{l}\text { Kaki terpeleset } \\
\text { masuk kedalam } \\
\text { mulut Ballmill }\end{array}$ & $\begin{array}{l}\text { Cidera karena bagian } \\
\text { tubuh masuk kedalam } \\
\text { Ballmill dan terbentur } \\
\text { besi area sekitar mulut } \\
\text { Ballmill } \\
\end{array}$ \\
\hline 17 & $\begin{array}{l}\text { Pemasangan corong pada lubang } \\
\text { Ballmill }\end{array}$ & $\begin{array}{l}\text { Persiapan } \\
\text { pembuatan KD cair, } \\
\text { slip dan glaze }\end{array}$ & $\begin{array}{l}\text { Pemasangan corong } \\
\text { harus membungkuk }\end{array}$ & $\begin{array}{l}\text { Sakit pinggang karena } \\
\text { posisi kerja tidak } \\
\text { ergonomi }\end{array}$ \\
\hline 18 & $\begin{array}{l}\text { Petugas mengangkat corong } \\
\text { setelah proses campur }\end{array}$ & $\begin{array}{l}\text { Persiapan } \\
\text { pembuatan KD cair, } \\
\text { slip dan glaze }\end{array}$ & $\begin{array}{l}\text { Posisi mengangkat } \\
\text { harus membungkuk } \\
\text { Corong licin karena } \\
\text { basah setelah proses }\end{array}$ & $\begin{array}{l}\text { Sakit pinggang, Kaki luka } \\
\text { dan cidera karena corong } \\
\text { menimpa kaki petugas }\end{array}$ \\
\hline 19 & $\begin{array}{l}\text { Petugas mengangkat penutup atas } \\
\text { Ballmill }\end{array}$ & Campur bahan baku & $\begin{array}{l}\text { Tangan terjepit } \\
\text { karena pegangan } \\
\text { tutup atas Ballmill } \\
\text { terlalu sempit } \\
\end{array}$ & Cidera pada jari tangan \\
\hline 20 & $\begin{array}{l}\text { Tombol operasioanal Hoist Crane } \\
\text { terpapar cipratan air dari proses } \\
\text { kerja dan kebersian area di } \\
\text { sekitarnya }\end{array}$ & $\begin{array}{l}\text { Pemindahan } \\
\text { magnite filter }\end{array}$ & $\begin{array}{l}\text { Petugas tersengat } \\
\text { listrik ketika } \\
\text { menekan tombol } \\
\text { operasional } \\
\end{array}$ & $\begin{array}{l}\text { Trauma jantung Dalam } \\
\text { kondisi tertentu dapat } \\
\text { menyebabkan kematian. }\end{array}$ \\
\hline 22 & $\begin{array}{l}\text { Kait Hoist Crane tidak ada } \\
\text { kuncipenahahan }\end{array}$ & $\begin{array}{l}\text { Pemindahan } \\
\text { magnite filter }\end{array}$ & $\begin{array}{l}\text { Petugas terimpa } \\
\text { Magnite Filter saat } \\
\text { diangkat } \\
\text { menggunakan hoist } \\
\text { crane }\end{array}$ & $\begin{array}{l}\text { Luka di kepala, pada } \\
\text { kondisi tertentu dapat } \\
\text { menyebabkan kematian }\end{array}$ \\
\hline
\end{tabular}


Tabel 1. Identifikasi Bahaya (Lanjutan)

\begin{tabular}{|c|l|l|l|l|}
\hline No & \multicolumn{1}{|c|}{ Identifikasi Aktivitas } & \multicolumn{1}{c|}{ Proses Kerja } & Identifikasi Bahaya & \multicolumn{1}{c|}{ Risiko } \\
\hline 23 & $\begin{array}{l}\text { Pengencangan mur pengencangan } \\
\text { pengunci vibrating sieve }\end{array}$ & $\begin{array}{l}\text { Set up mesin } \\
\text { vibrating sieve } \\
\text { saat mengencangan } \\
\text { mur dengan kunci } \\
\text { dan Kunci mengenai } \\
\text { kepala }\end{array}$ & $\begin{array}{l}\text { Cidera kepala akibat } \\
\text { hantaman kunci }\end{array}$ \\
\hline 24 & $\begin{array}{l}\text { Petugas mendorong hopper } \\
\text { penampung kude ke mulut } \\
\text { blunger }\end{array}$ & $\begin{array}{l}\text { Giling kude kering } \\
\text { Slip }\end{array}$ & $\begin{array}{l}\text { Roda } \text { hopper masuk } \\
\text { ke dalam mulut } \\
\text { mesin blunger }\end{array}$ & $\begin{array}{l}\text { Cidera karena badan } \\
\text { kaget dan menghantam } \\
\text { hopper }\end{array}$ \\
\hline 25 & $\begin{array}{l}\text { Petugas menggetok bongkahan } \\
\text { bahan baku yang besar menjadi } \\
\text { pecahan yang lebih kecil }\end{array}$ & $\begin{array}{l}\text { Seleksi ukuran } \\
\text { bongkahan bahan } \\
\text { baku }\end{array}$ & $\begin{array}{l}\text { Tangan terkena } \\
\text { hantaman palu saat } \\
\text { petugas memukul } \\
\text { bongkahan }\end{array}$ & Tangan cidera \\
\hline
\end{tabular}

\subsection{Penilaian Resiko}

Setelah melakukan identifikasi resiko maka tahap selanjutnya adalah melakukan penilaian resiko. Penilaian ini bertujuan untuk mengetahui area mana yang memiliki potensi resiko Ekstrim, Tinggi, sedang, dan Rendah. Dibawah ini adalah hasil dari penilaian resiko. Dimana penilaian ini dilakukan oleh peneliti, Ahli K3 perusahaan, dan pimpinan produksi Tabel 2 Penilaian Resiko

\begin{tabular}{|c|c|c|c|c|c|}
\hline \multirow{2}{*}{ No } & Paparan & Peluang & Konsekuensi & \multirow{2}{*}{ Tingkatan Risiko (E x L x C) } & \multirow{2}{*}{ Tingkatan Risiko } \\
\hline & $(\mathrm{E})$ & $(\mathrm{L})$ & $(\mathrm{C})$ & & \\
\hline 1 & 6 & 0.3 & 20 & 36 & Ekstrim \\
\hline 2 & 6 & 0.3 & 20 & 36 & Ekstrim \\
\hline 3 & 6 & 0.3 & 10 & 18 & Tinggi \\
\hline 4 & 3 & 0.6 & 10 & 18 & Tinggi \\
\hline 5 & 6 & 0.6 & 5 & 18 & Tinggi \\
\hline 6 & 3 & 0.6 & 10 & 18 & Tinggi \\
\hline 7 & 3 & 0.6 & 10 & 18 & Tinggi \\
\hline 8 & 3 & 0.3 & 20 & 18 & Tinggi \\
\hline 9 & 6 & 0.6 & 5 & 18 & Tinggi \\
\hline 10 & 3 & 0.3 & 20 & 18 & Tinggi \\
\hline 11 & 6 & 0.6 & 5 & 18 & Tinggi \\
\hline 12 & 3 & 0.6 & 10 & 18 & Tinggi \\
\hline 13 & 6 & 0.3 & 10 & 18 & Tinggi \\
\hline 14 & 3 & 0.3 & 10 & 9 & Sedang \\
\hline 15 & 3 & 0.6 & 5 & 9 & Sedang \\
\hline 16 & 3 & 0.6 & 5 & 9 & Sedang \\
\hline 17 & 3 & 0.6 & 5 & 9 & Sedang \\
\hline 18 & 3 & 0.6 & 5 & 9 & Sedang \\
\hline 19 & 3 & 0.6 & 5 & 9 & Sedang \\
\hline 20 & 3 & 0.1 & 20 & 6 & Sedang \\
\hline 21 & 3 & 0.1 & 20 & 6 & Sedang \\
\hline 22 & 3 & 0.3 & 5 & 4.5 & Sedang \\
\hline 23 & 3 & 0.3 & 5 & 4.5 & Sedang \\
\hline 24 & 3 & 0.3 & 2 & 1.8 & Rendah \\
\hline 25 & 6 & 0.1 & 2 & 1.2 & Rendah \\
\hline
\end{tabular}

Berdasarkan penilaian risiko yang dilakukan pada Tabel 2 diatas, didapatkan 4 (empat) macam risiko dengan nilai yang berbeda, di urutan pertama terdapat Risiko Tinggi sebesar 11 risiko, urutan kedua terdapat Risiko Sedang sebesar 10 risiko, urutan ketiga terdapat Risiko Ekstrim sebesar 2 risiko dan urutan keempat terdapat Risiko Rendah sebesar 2 risiko. 


\subsection{Analisa Akar Penyebab}

Risiko yang dianalisa dengan metode FTA ini adalah risiko ranking 1 sampai risiko peringkat 13 yang memiliki nilai risiko ekstrim dan tinggi. Analisa risiko dengan metode FTA ini dapat dilihat pada Gambar dibawah ini.

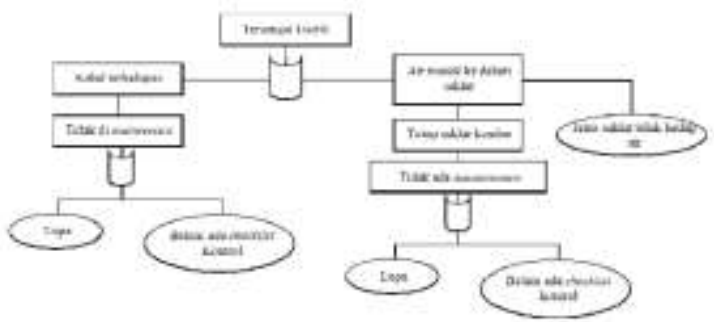

Gambar 2. FTA Diagram Resiko peringkat 1

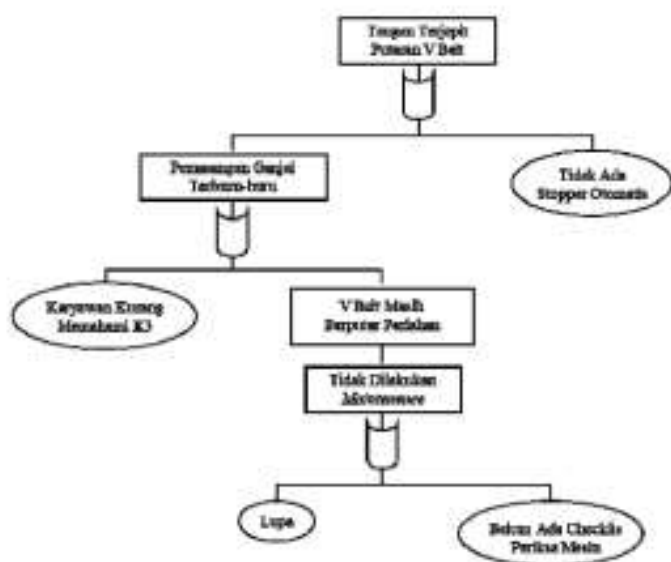

Gambar 3. FTA Diagram Resiko peringkat 2

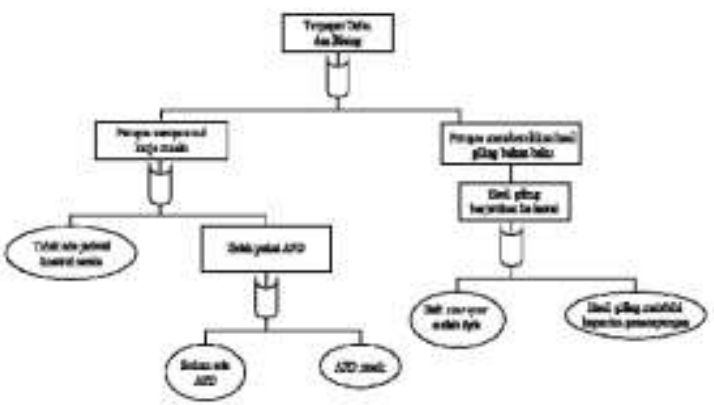

Gambar 4. FTA Diagram Resiko peringkat 3 


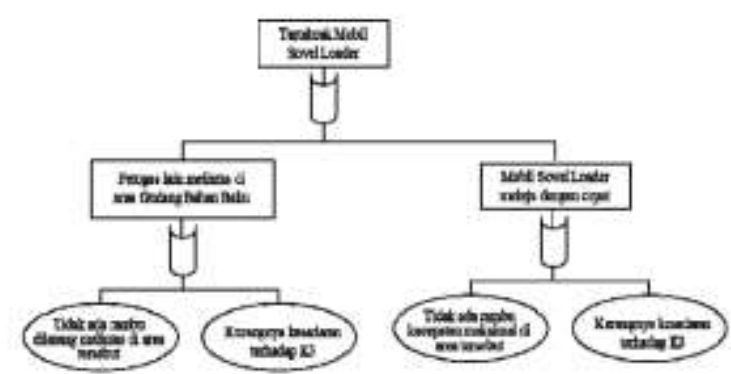

Gambar 5. FTA Diagram Resiko peringkat 4

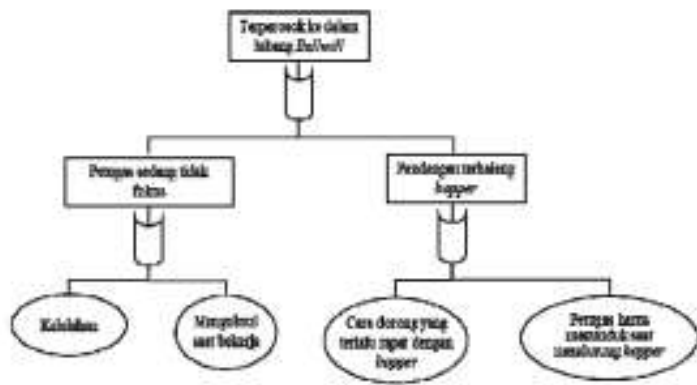

Gambar 6. FTA Diagram Resiko peringkat 5

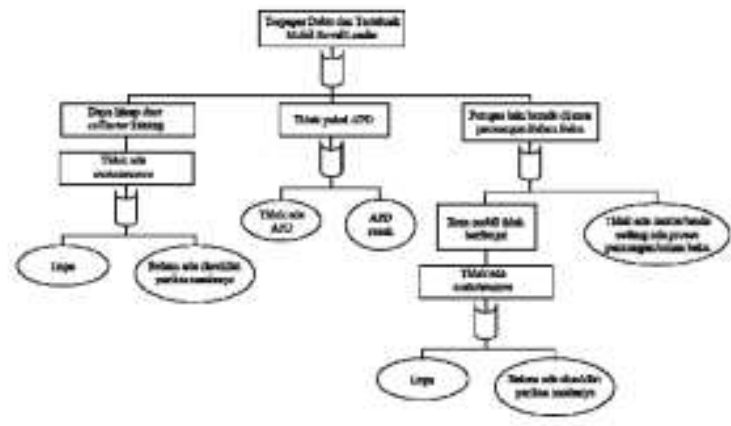

Gambar 7. FTA Diagram Resiko peringkat 6

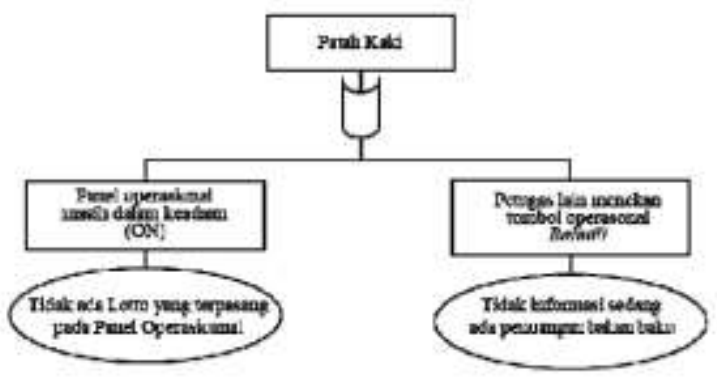

Gambar 8. FTA Diagram Resiko peringkat 7 


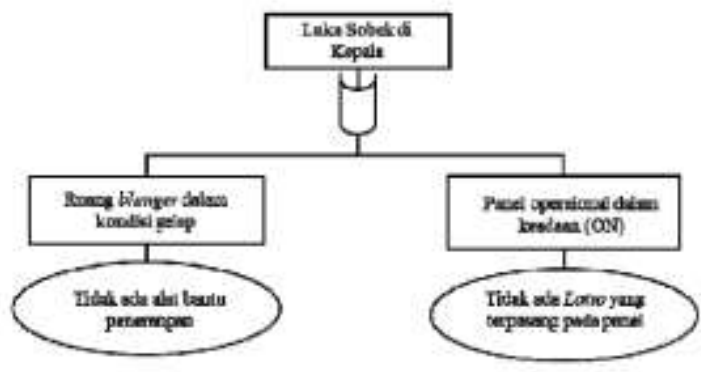

Gambar 9. FTA Diagram Resiko peringkat 8

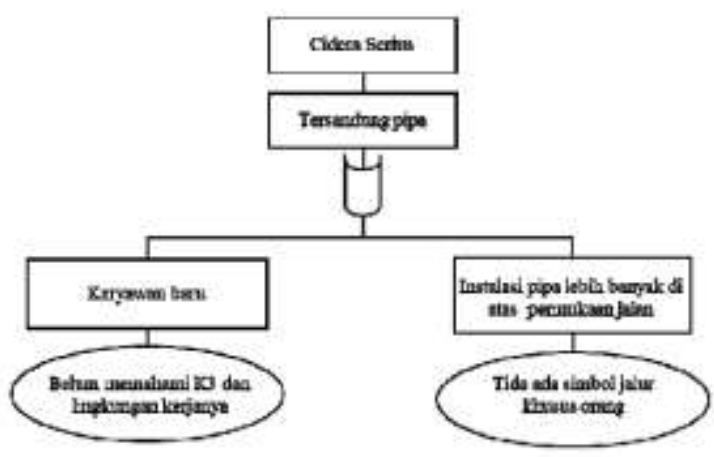

Gambar 10. FTA Diagram Resiko peringkat 9

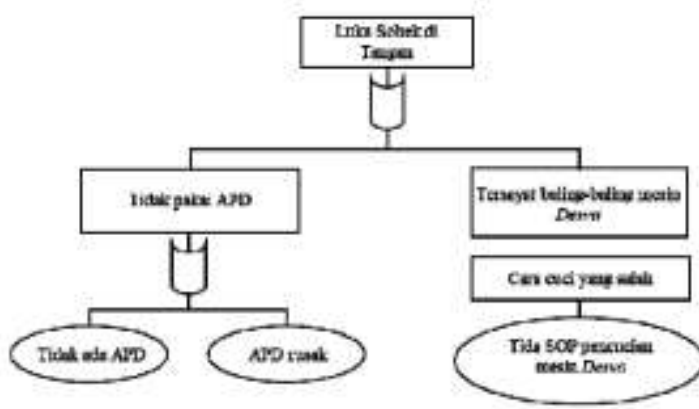

Gambar 11. FTA Diagram Resiko peringkat 10

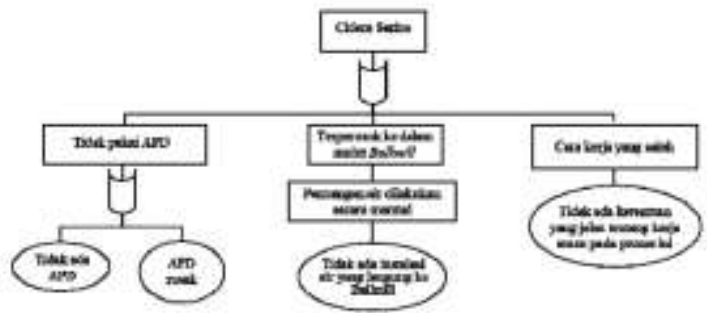

Gambar 12. FTA Diagram Resiko peringkat 11 


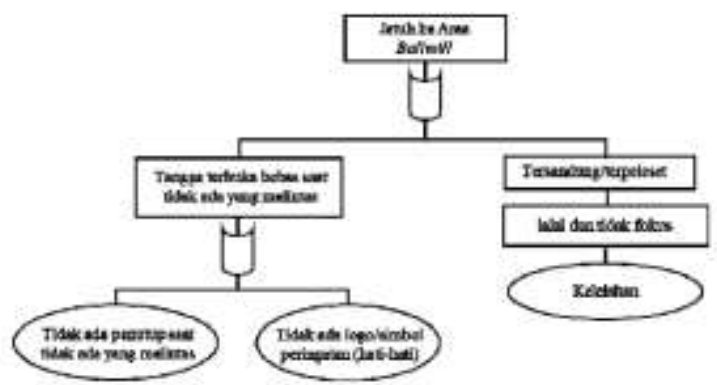

Gambar 13. FTA Diagram Resiko peringkat 12

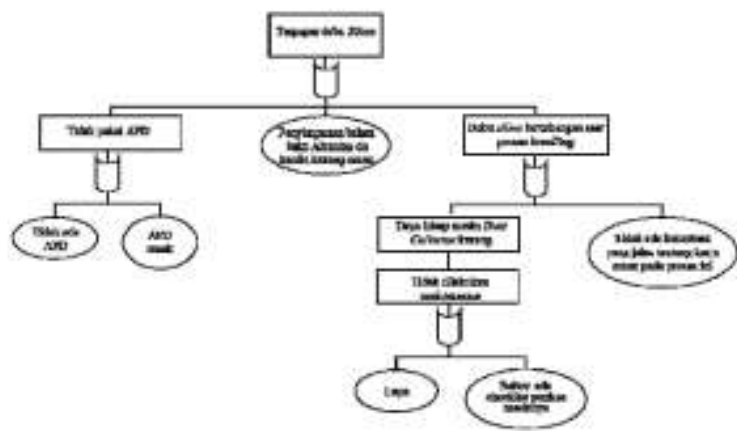

Gambar 14. FTA Diagram Resiko peringkat 13

\subsection{Pengendalian Resiko}

Tingkatan risiko yang dihasilkan dari penilaian risiko yang kemudian dianalisa akar penyebabnya dengan metode Fault Tree Analysis (FTA) diatas, maka dapat dijelaskan secara jelas pengendalian yang sudah ada (existing control), apabila masih kurang maka perlu dibuat pengendalian tambahan (additional control) sebagai usulan perbaikan serta perubahan nilai dan perubahan tingkatan risikonya pada Tabel berikut ini.

Tabel 3. Pengendalian Resiko potensi bahaya

\begin{tabular}{|c|c|c|c|c|c|c|c|c|c|}
\hline No & $\begin{array}{l}\text { Identifikasi } \\
\text { Aktifitas }\end{array}$ & $\begin{array}{l}\text { Nilai } \\
\text { Resiko }\end{array}$ & $\begin{array}{c}\text { Tingkatan } \\
\text { Resiko }\end{array}$ & Existing Control & $\begin{array}{l}\text { Nilai } \\
\text { Resiko }\end{array}$ & $\begin{array}{c}\text { Tingkatan } \\
\text { Resiko }\end{array}$ & Usulan Perbaikan & $\begin{array}{l}\text { Nilai } \\
\text { Resiko }\end{array}$ & $\begin{array}{c}\text { Tingkatan } \\
\text { Resiko }\end{array}$ \\
\hline 1 & $\begin{array}{l}\text { Lokasi tombol } \\
\text { power } \\
\text { bertegangan } \\
\text { ( } 880 \text { Volt) } \\
\text { mesin } \\
\text { vibrating } \\
\text { sieve berada } \\
\text { di bawah } \\
\text { mesin dan } \\
\text { tidak ada } \\
\text { penutupnya }\end{array}$ & 36 & Ekstrim & $\begin{array}{l}\text { Pemilihan power } \\
\text { botton yang khusus } \\
\text { tahan air (Water } \\
\text { Ressistance) }\end{array}$ & 12 & Tinggi & $\begin{array}{l}\text { Pengecekkan secara } \\
\text { berkala kondisi power } \\
\text { botton dengan } \\
\text { Checklist Periksa } \\
\text { Mesin }\end{array}$ & 6 & Sedang \\
\hline 2 & $\begin{array}{l}\text { Petugas } \\
\text { melepas } \\
\text { ganjal } V \text {-Belt }\end{array}$ & 36 & Ekstrim & $\begin{array}{l}\text { Ganjal kayu diganti } \\
\text { dengan bahan anti } \\
\text { Slip (karet) }\end{array}$ & 12 & Tinggi & $\begin{array}{l}\text { Dibuat limit switch } \\
\text { agar Ballmill berhenti } \\
\text { pada posisi yang tepat } \\
\text { tanpa harus diganjal }\end{array}$ & 6 & Sedang \\
\hline 3 & $\begin{array}{l}\text { Petugas } \\
\text { standby di } \\
\text { area Crusher }\end{array}$ & 18 & Tinggi & $\begin{array}{l}\text { Penyediaan APD } \\
\text { (Masker dan Ear } \\
\text { Plug) }\end{array}$ & 6 & Sedang & $\begin{array}{l}\text { Dibuat jadwal untuk } \\
\text { kontrol mesin Crusher }\end{array}$ & 3 & Sedang \\
\hline 4 & $\begin{array}{l}\text { Pemindahan } \\
\text { hasil giling } \\
\text { dengan } \\
\text { menggunakan } \\
\text { sovel loader } \\
\text { ke gudang } \\
\text { bahan baku }\end{array}$ & 18 & Tinggi & $\begin{array}{l}\text { Penyediaan APD } \\
\text { (Masker dan } \\
\text { Earplug) \& Dibuat } \\
\text { j alur khusus untuk } \\
\text { Sovel Loader }\end{array}$ & 9 & Sedang & $\begin{array}{l}\text { Memberi ketentuan } \\
\text { batas maksimal } \\
\text { kecepatan mobil Sovel } \\
\text { Loader dan } \\
\text { Dibuatkan Checklist } \\
\text { perika mobil Sovel } \\
\text { Loader }\end{array}$ & 3 & Sedang \\
\hline
\end{tabular}


Tabel 3. Pengendalian Resiko potensi bahaya (Lanjutan)

\begin{tabular}{|c|c|c|c|c|c|c|c|c|c|}
\hline No & $\begin{array}{c}\text { Identifikasi } \\
\text { Aktifitas }\end{array}$ & $\begin{array}{l}\text { Nilai } \\
\text { Resiko }\end{array}$ & $\begin{array}{c}\text { Tingkatan } \\
\text { Resiko }\end{array}$ & Existing Control & $\begin{array}{c}\text { Nilai } \\
\text { Resiko }\end{array}$ & $\begin{array}{c}\text { Tingkatan } \\
\text { Resiko }\end{array}$ & Usulan Perbaikan & $\begin{array}{l}\text { Nilai } \\
\text { Resiko }\end{array}$ & $\begin{array}{c}\text { Tingkatan } \\
\text { Resiko }\end{array}$ \\
\hline 5 & $\begin{array}{l}\text { Pemasangan } \\
\text { hopper pada } \\
\text { lubang } \\
\text { Ballmill }\end{array}$ & 18 & Tinggi & $\begin{array}{l}\text { Penyediaan APD } \\
\text { (Helmet dan sepatu } \\
\text { boot karet) }\end{array}$ & 9 & Sedang & $\begin{array}{l}\text { Dibuat stopper pada } \\
\text { rel lintasan Hopper } \\
\text { posisi samping lubang } \\
\text { corong yang bisa } \\
\text { dibuka dan ditutup } \\
\text { sesuai kebutuhan }\end{array}$ & 3 & Sedang \\
\hline 6 & $\begin{array}{l}\text { Penuangan } \\
\text { bahan KD, } \\
\text { Slip dan glaze } \\
\text { kedalam } \\
\text { hopper }\end{array}$ & 18 & Tinggi & $\begin{array}{l}\text { 1. Pengadaan APD } \\
\text { ( Masker, Earplug } \\
\text { dan Safety Shoes ) } \\
\text { 2. Dibuatkan j alur } \\
\text { khusus untuk sovel } \\
\text { loader } \\
\text { 3. Sudah dibuatkan } \\
\text { stopper untuk sovel } \\
\text { loader }\end{array}$ & 9 & Sedang & $\begin{array}{l}\text { Dibuatkan rambu- } \\
\text { rambu sedang proses } \\
\text { isi Ballmill agar tidak } \\
\text { ada petugas yang } \\
\text { melintas di area } \\
\text { pengisian }\end{array}$ & 3 & Sedang \\
\hline 7 & $\begin{array}{l}\text { Petugas } \\
\text { membersihkan } \\
\text { mulut tutup } \\
\text { Ballmill }\end{array}$ & 18 & Tinggi & $\begin{array}{l}\text { Dibuatkan kunci } \\
\text { untuk Panel } \\
\text { Operasional }\end{array}$ & 9 & Sedang & $\begin{array}{l}\text { Kunci panel dibawa } \\
\text { oleh petugas yang } \\
\text { mengisi Ballmill }\end{array}$ & 3 & Sedang \\
\hline 8 & $\begin{array}{l}\text { Pencucian } \\
\text { ruang mesin } \\
\text { Blunger }\end{array}$ & 18 & Tinggi & $\begin{array}{l}\text { 1. Dibuatkan kunci } \\
\text { khusus untuk panel } \\
\text { operasi mesin } \\
\text { Blunger } \\
\text { 2. Pengadaan APD } \\
\text { 3. Saat mencuci } \\
\text { ruang Blunger } \\
\text { dibantu penerangan } \\
\text { lampu }\end{array}$ & 6 & Sedang & $\begin{array}{l}\text { 1. Kunci panel operasi } \\
\text { mesin Blunger } \\
\text { dipegang oleh petugas } \\
\text { yang mencuci mesin } \\
\text { Blunger } \\
\text { 2. Pemasangan Lotto } \\
\text { pada panel } \\
\text { operasioanal }\end{array}$ & 3 & Sedang \\
\hline 9 & $\begin{array}{l}\text { Instalasi } \\
\text { perpipaan } \\
\text { berada } \\
\text { dipermukaan } \\
\text { Lantai }\end{array}$ & 18 & Tinggi & $\begin{array}{l}\text { Pembuatan } \mathrm{j} \text { alur } / \mathrm{j} \\
\text { alan khusus untuk } \\
\text { orang }\end{array}$ & 9 & Sedang & $\begin{array}{l}\text { 1. Pemberian simbol } \\
\text { ada jalur khusus orang } \\
\text { 2. Pemasangan } \\
\text { rambu-rambu dilarang } \\
\text { melintas pada area } \\
\text { mesin kecuali petugas }\end{array}$ & 3 & Sedang \\
\hline 10 & $\begin{array}{l}\text { Setting dan } \\
\text { cuci mesin } \\
\text { Desva }\end{array}$ & 18 & Tinggi & $\begin{array}{l}\text { - Dibuatkan cover } \\
\text { untuk penutup } \\
\text { baling - baling } \\
\text { mesin Desva saat } \\
\text { tidak dipakai }\end{array}$ & 6 & Sedang & $\begin{array}{l}\text { 1. Pengadaan APD } \\
\text { (Sarung tangan anti } \\
\text { sobek) } \\
\text { 2. Diberi rambu- } \\
\text { rambu (hati- hati) di } \\
\text { lokasi mesin desva } \\
\text { 3. Pembuatan Daftar } \\
\text { Isntruksi Kerja khusus } \\
\text { setting dan pencucian } \\
\text { mesin desva }\end{array}$ & 3 & Sedang \\
\hline 11 & $\begin{array}{l}\text { Petugas } \\
\text { menuangkan } \\
\text { air ke dalam } \\
\text { Ballmill }\end{array}$ & 18 & Tinggi & $\begin{array}{l}\text { Pengadaan APD } \\
\text { (Sepatu boot karet } \\
\text { dan helmet) }\end{array}$ & 9 & Sedang & $\begin{array}{l}\text { Dibuat instalasi pipa } \\
\text { yang mengarah ke } \\
\text { dalam Ballmill }\end{array}$ & 3 & Sedang \\
\hline 12 & $\begin{array}{l}\text { Terdapat } \\
\text { undakan pada } \\
\text { tangga } \\
\text { menuju ke } \\
\text { area Ballmill } \\
\text { namun tidak } \\
\text { ada }\end{array}$ & 18 & Tinggi & $\begin{array}{l}\text { - Pemberian tanda } \\
\text { Zebra Cross kuning } \\
\text { hitam agar menjadi } \\
\text { perhatian bagi } \\
\text { orang disekitar area } \\
\text { tersebut }\end{array}$ & 3 & Sedang & $\begin{array}{l}\text { Pemasangan pintu } \\
\text { untuk tangga menuju } \\
\text { ke area Ballmill }\end{array}$ & 1,5 & Sedang \\
\hline 13 & $\begin{array}{l}\text { Penuangan } \\
\text { bahan Alumin } \\
\text { dan Kaolin }\end{array}$ & 18 & Tinggi & $\begin{array}{l}\text { - Pengadaan APD } \\
\text { (Masker)Penuangan } \\
\text { dilakukan di area } \\
\text { Dust Collector }\end{array}$ & 6 & Sedang & $\begin{array}{l}\text { Pengecekkan secara } \\
\text { berkala daya hisap } \\
\text { mesin Dust Collector }\end{array}$ & 3 & Sedang \\
\hline
\end{tabular}


Berdasarkan table diatas dapat dilihat pengurangan nilai risiko-risiko yang ada (Existing control) setelah dilakukan oleh manajemen perusahaan. Untuk lebih meningkat pengendalian terhadap resiko-resiko yang ada maka perlu ditamahkan beberapa pengendalian tambahan (additional control) sebagai usulan perbaikan, untuk mengurangi nilai resiko dan tingkatan resikonya. Penting bagi manajemen untuk mengurangi resiko yang ada sehingga semua aktivitas kerja memiliki nilai resiko rendah.

\section{SIMPULAN}

Berdasarkan hasil penelitian dan pembahasan yang telah dikemukakan pada bab sebelumnya maka disimpulkan bahwa:

1. PT Surya Toto Indonesia Tbk sudah menerapkan SMK3 sejak tanggal 10 Agustus 2010 sesuai dengan surat keputusan (SK) Kepala Dinas Tenaga Kerja dan Transmigrasi. No.566/Kep.6064/DISNAKERTRANS. Dengan melakukan tindakan:

a. Penyelidikan menyeluruh terhadap kecelakaan kerja di dalam dan di luar pabrik serta analisis dan dampaknya masing-masing.

b. Identifikasi sumber bahaya di tempat kerja, termasuk peralatan, prosedur dan faktor manusia yang di dokumentasikan ke dalam ketentuan kerja.

c. Membuat ketentuan untuk penyimpanan bahan B3 (bahan berbahaya dan beracun).

d. Melatih karyawan PT. Surya Toto Indonesia Tbk divisi Sanitary secara tepat tentang prosedur, alat-alat dan fasilitas saat keadaan darurat.

e. Melaksanakan pemeriksaan dan peninjauan rutin terhadap semua prosedur manajemen keselamatan mulai dari awal investigasi hingga pelaksanaan pengukuran, pelaksanaan modifikasi atau perubahan atau suplementasi jika diperlukan.

2. Potensi bahaya yang terdapat di PT Surya Toto Indonesia Tbk divisi Sanitary, seksi Slip Preparing adalah, potensi rendah sebanyak 2 risiko, potensi sedang 10 risiko, potensi tinggi sebanyak 11 risiko dan potensi ekstrim sebanyak 2 risiko.

3. PT Surya Toto Indonesia Tbk divisi Sanitary megidentifikasi potensi bahaya dengan cara mengelompokkan aktivitas dan lokasi yang memiliki potensi bahaya namun belum ada nilai risiko bahayanya. Pengendalian bahaya yang dilakukan oleh PT Surya Toto Indonesia Tbk divisi Sanitary adalah pengendalian bahaya secara administratif (daftar instruksi kerja), penyediaan alat pelindung diri (APD) dan disertai dengan pengawasan tim P2K3 (inspeksi manajemen setiap bulan).

Saran yang penulis berikan adalah sebagai berikut:

1. Untuk penelitian selanjutnya, kebiasaan atau cara kerja karyawan yang dinilai berbahaya dapat menjadi pertimbangan untuk menentukan nilai risiko.

2. Untuk menunjang hasil pengamatan perlu dilakukan wawancara kepad karyawan yang bekerja di seksi Slip Preparing tentang kendala terkait K3.

3. Untuk penelitian selanjutnya dapat menggunakan metode HIRARC dan FTA ini untuk seksi atau departemen lainnya, seperti Engineering dan Utility.

4. Untuk penelitian selanjutnya ISO 45001 tentang Keselamatan dan Kesehatan dapat dijadikan referensi.

\section{DAFTAR PUSTAKA}

Budiono, A.M.S. (2005). Bunga Rampai Higiene Perusahaan Ergonomi (HIPERKES) dan Kesehatan dan Keselamatan Kerja. Semarang: Badan Penerbit Universitas Diponegoro.

Darmawi, S. (2016). Manajemen Risiko. Jakarta: Bumi Aksara

Dharmawirawan, D.A., \& Modjo, R. (2012). Identifikasi Bahaya Keselamatan dan Kesehatan Kerja pada Penangkapan Ikan Nelayan Muroami. Jurnal Kesehatan Masyarakat Nasional, Vol. 6, No. 4, Februari 2012.

Ghaisani, H., \& Nawawinetu, E.D., (2014). Identifikasi Bahaya, Penilaian Risiko dan Pengendalian Risiko Pada Proses Blasting di PT Cibaliung Sumber daya, Banten. The Indonesian Journal of Occptional Safety and Health, Vol. 3, No. 1, Jan-Jun 
2014:107-116.

Ihsan, T., Edwin, T., \& Irawan R.O., (2016). Analisis Risiko K3 dengan Metode HIRARC pada Area Produksi PT Cahaya Murni Andalas Permai. Jurnal Kesehatan Masyarakat Andalas, Vol. 10, No. 2, Hal. 179-185.

International Labour Organizaton. (2013). Sistem Manajemen Keselamatan dan Kesehatan Kerja.Jakarta: International Labour Office

Irawan, S., Panjaitan, T.W.S., \& Bendatu, L.Y., (2015).

Penyusunan Hazard Identification Risk Assessment and Risk Control (HIRARC) Di PT. X, Jurnal Titra, Vol. 3, No 1, Januari 2015, pp. 15-18.

Mallapiang, F., \& Samosir, I.A., (2014). Analisis Potensi Bahaya dan Pengendaliannya Dengan Metode HIRAC. Public Health Science Journal, Vol. VI, No. 2, JuliDesember 2014

Peraturan Menteri Tenaga Kerja Republik Indonesia No.

Pitasari, G.P., Wahyuning, C.S., \& Desrianty, A., (2014). Analisis Kecelakaan Kerja Untuk Meminimisasi Potensi Bahaya Menggunakan Metode Hazard and Operability dan Fault Tree Analysis (Studi Kasus Di PT X). Jurnal Online Institut Teknologi Nasional, Vol. 2, No. 2, Oktober 2014.

Primasari, A.D., Denny, H.M., \& Ekawati, (2016).

Penerapan Hazard Identification Risk Assessment and Risk Control (HIRARC) Sebagai Pengendalian Potensi Kecelakaan Kerja di Bagian Produksi Body Bus PT. X Magelang. Jurnal Kesehatan Masyarakat, Vol. 4, No. 1, Januari 2016

Purnama, D.S., (2015). Analisia Penerapan Metode HIRARC (Hazard Identification Risk Assessment and Risk Control) dan HAZOPS (Hazard and Operability Study) Dalam Kegiatan Identifikasi Potensi Bahaya dan Resiko Pada Proses Unloading Unit di PT. Toyota Astra Motor. Jurnal PASTI, Vol. IX, No. 3, 311-319.

Ramli, S. (2010) Pedoman praktis Manajemen Risiko dalam prespektif K3OHS Risk Management. Jakarta: Dian Rakyat.

Restuputri, D.P., \& Sari, R.P.D., (2015). Analisis Kecelakaan Kerja dengan Menggunakan Metode Hazard and Operability Study (HAZOP). Jurnal Ilmiah Teknik Industri, Vol. 14, No. 1, Juni 2015.

Roehan, K.R.K., Yuniar., \& Desrianty, A., (2014).

Usulan Perbaikan Sistem Manajemen Keselamatan dan Kesehatan Kerja (SMK3) Menggunakan Metode Hazard Identification and Risk Assesment (HIRA). Jurusan Teknik Industri Itenas, Vol.02 No.02, April 2014

Suardi, R. (2007). Manajemen Risiko - Panduan Penerapan Berdasarkan OHSAS 18001 dan Permenaker 05/1996. Jakarta: PPM.

Supriyadi., \& Ramdan, F., (2017). Identifikasi Bahaya dan Penilaian Risiko Pada Divisi Boiler Menggunakan Metode Hazard Identification Risk Assessment and Risk Control (HIRARC). Journal of Industrial Hygiene and Occupational Health, Vol.1, No. 2, April 2017

Susihono W. \& Feni, A.R., (2013). Penerapan Sistem Manajemen Keselamatan Dan Kesehatan Kerja (K3) dan Identifikasi Potensi Bahaya Kerja. Spektrum Industri, 2013, Vol. 11, No. 2, 117 - 242

Suyono, K.Z., \& Nawawinetu, E.D., (2013). Hubungan Antara Faktor Pembentuk Budaya Keselamatan Kerja Dengan Safety Behavior di PT Dok dan Perkapalan Surabaya Unit Hull Construction. The Indonesian Journal of Occupational Safety and Health, Vol. 2, No. 1, Jan-Jun 2013: 67-74.

Evaluasi Kesehatan dan Keselamatan Kerja dengan Metode HIRARC pada PT. Charoen Pokphand Indonesia. Jurnal Tirta, Vol. 3, No. 1, Januari 2015, pp. 29-34.

Zamani, W., (2014). Identifikasi Bahaya Kecelakaan Unit Spinning I Menggunakan Metode HIRARC di PT. Sinar Pantja Djaja. Unnes Journal of Public Health, Vol. 3, No. 1, 2014. 